\title{
ORRGNAL PAPERS
}

報 文

(6)
比熱を温度の函数とした恒水温断熱冷却

線についで

佐 藤 敬 夫**・嗃 藤 悦 雄***

要旨：常圧の下での空気と水の共存系についての断熱冷却線に関して, 水温は従来 通り一定と看做した上で, 架気扣よび水蒸気の比熱を共に温度の四数として扱つて, 温度の広範囲に亘つて使用できる式を導き，更に線図の形にして従来のるの〉補外曲 線などとの比較を行つた。ついでに，この場合にも断熱館和線と断熱冷却 (增湿) 線 そは同じあのであることの証明を附し，その意義に言改した。
いえばそれぞれて0.24と0.45 を採用しているものの方が 適当であるよらに思ら。

\section{$\S 3$ 温度の函数とし た $\boldsymbol{C}_{\text {air }}$ と $\boldsymbol{C}_{\text {vap }}$}

\section{$\S 1$ 緒 言}

水と空気の系では工学的精度で水温一定と認め得ると いら仮定て断熱冷却線の式括よび湿应図表上の線图が提 出されているが，空気扣よび氷蒸気の比熱は共に一定と して扱われている。

そして，このような埸合には，同一温度を断熱能和温 度”として共有する点(湿润空気の状態)を結び合せた線 として定義された断熱飽和線と，状態变移のPath curve として定義された断熱冷却線とは，結局同じのである そいろ数式的証明も為されている゙る。

しかし乍ら，筀気抽よ゙水蒸気の比熱は共に温度によ つて变るものであるから，温度の広範囲にわたつて扱 場合には，これらの比熱を温度の函数として式怙よび線 图を作つた方がよい上らに思われる。

常王下の水と筀気の系について, 水温法従来通り一定 として，上記の計算を行つた式とそれを線図にして従来 のるのを高温に補外した線図括よひ高温との平均比熱で 扱つたもの等と比較した結果をここに報告する。

\section{$\$ 2$ 從来のものについて}

従来提出されているすのに低温用と呼ばれるるのと高 温用と呼ばれているすのとがあるが，前者は $0 \sim 120^{\circ} \mathrm{C}$, 後者は $0 \sim 400^{\circ} \mathrm{C}$ 位のるのであつて, それ以上の高温に 亘るるのは見受けられない。

そして, 従来の低温用の埸合に, 架気の比熱を $C_{\mathrm{air}}=$ 0.24 , 水蒸気の比熱を $C_{\mathrm{vap}}=0.46$ としているものが多 いが，比熱を温度の 2 次式として与えたデーダによつ て梌すると，0.24 は大体 $18 \sim 100^{\circ} \mathrm{C} の C_{\text {air }}$ の平均で あるのに対して, 0.46 は大体 $18 \sim 300^{\circ} \mathrm{C}$ の $C_{\text {vap }}$ の平均 に相当し， $18 \sim 100^{\circ} \mathrm{C}$ の $C_{\text {vap }}$ の平均は 0.447 位である から，0〜 $120^{\circ} \mathrm{C}$ 位のいかゆる低温用としては，何方かと

\footnotetext{
* 昭和 28 年 6 月 19 日要理
}

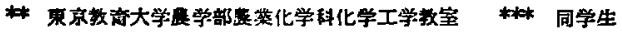

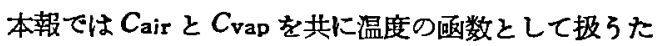
めに, モル熱容量を絶対温度の 2 次式として0〜 $1800^{\circ} \mathrm{K}$ に亘つて $1.0 \%$ の誤差䇶囲で与えたデーダから換算し $\tau \mathrm{kcal} / \mathrm{kg}^{\circ} \mathrm{C}$ の $C_{\text {air }}(t)$ と $C_{\text {vap }}(t)$ をそれぞれ $C_{\text {air }}(t)=0.2347+0.0000634 t-0.0000000158 t^{2}$

$C_{\text {vap }}(t)=0.43115+0.000172 t-0.00000001905 t^{2}$ として使用した。

\section{§4 比㛙を温度の函數とした 亘水温の断熱飽和楾の式}

或る湿潤些気 $\left(H_{i}, t_{i}\right)$ か $\left(H_{s}, t_{s}\right)$ を断熱鴒和状態 として有する任意の一つの状態であるとして式を作れば よいので, 温度 $t_{s}$ に於ける蒸発潜熱を $r_{\text {っとして }}$

$$
\begin{gathered}
\left(H_{s}-H_{i}\right)\left\{r_{s}+\int_{t_{s}}^{t_{s}} C_{\mathrm{vap}}(t) d t\right\} \\
=-\int_{t_{i}}^{t_{s}}\left\{C_{\mathrm{air}}(t)+H_{i} C_{\mathrm{vap}}(t)\right\} d t \\
\text { 即方 } r_{s}\left(H_{s}-H_{i}\right)=\int_{t_{s}}^{t_{i}} C_{\mathrm{air}}(t) d t+H_{i} \int_{t_{s}}^{t_{i}} C_{\mathrm{vap}}(t) d t(3)
\end{gathered}
$$

§5 比熱を温度の目数とした 佰水温の断熱冷却線の式

或る任意の状態 $(H, t)$ なる湿潤空気が，その断熱飽 和温度 $t_{\mathrm{s}}$ にある水と接触して, その水温が 終始一定に 保たれるるのとして，断熱下で飽和状態へ向つて变化す る $d H$ とdt との関俰式を作ればよいのて

$$
\begin{aligned}
& \left\{r_{d}+\int_{d_{d}}^{t} C_{\mathrm{vap}}(t) d t\right\} d H \\
& =-\left\{C_{\mathrm{air}}(t)+H \cdot C_{\mathrm{vap}}(t)\right\} d t
\end{aligned}
$$

\section{\$6 比熱を温度の函数とした断熱悇和楾 と断熱冷却線との同一性について}

恒水温断熱冷却線の (4) 式は恒水温断熱飽和線の 
式に導かれ両者は全く同一であることを証明しておく。 即ち，(4) 式は

$$
\frac{d H}{d t}+\frac{C_{\mathrm{vap}}(t)}{r_{s}+\int_{t_{s}}^{t} C_{\mathrm{vap}}(t) d t} \cdot H=-\frac{C_{\mathrm{air}}(t)}{r_{s}+\int_{t_{s}}^{t} C_{\mathrm{vap}}(t) d t}
$$

そなり、これは一次線形で容易に琵分されい，

$$
H=\frac{C-\int C_{\text {air }}(t) d t}{r_{s}+\int_{t_{s}}^{t} C_{\text {vap }}(t) d t}
$$

これに $\left(H_{s}, t_{s}\right)$ を入れて稍分常数 $C$ を決めると

$$
C=r_{s} H_{s}+\mid \int C_{\text {air }}(t) d t t_{t=t_{s}}
$$

この（6）式を上式（5）に入れて整理すると

$$
r_{s}\left(H_{s}-H\right)=\int_{t_{s}}^{t} C_{\mathrm{air}}(t) d t+H \int_{t_{s}}^{t} C_{\mathrm{vad}}(t) d t
$$

そなる。この（7）式で $H=H_{i} ， t=t_{\text {t }}$ とすれいは（3） 式と全く同一であるので，これで証明を終つたことにな る。

\section{$\$ 7$ 上記の証明の意義}

恒水温の場合について，比熱を温度の函数としても， 断熱悇和線の（3）式と断熱冷却線の（4）式とは全く同 一であるので，この線を画く時に(3) 式によつて各々の
$\left(H_{a}, t_{s}\right)$ に対して $\left(H_{t}, t_{t}\right)$ を幾つか算定して Smooth curve に結んだあのを， $\left(H_{1}, t_{1}\right)$ から飽和でない $\left(H_{2}\right.$, $\left.t_{2}\right)$ までの Path curve としてそのま〉使用しても差支 えなく、そのための誤差は生しえたい、䝘詿1)。

\section{8計算結果の線四および比较}

(3) 式に（1），(2) 両式を入れて

$$
\begin{aligned}
& H_{i}=\frac{r_{s} H_{s}-\left\{0.2347\left(t_{t}-t_{s}\right)\right.}{r_{s}+\left\{0.43115\left(t_{t}-t_{s}\right)\right.} \\
& \left.+0.0317 \times 10^{-3}\left(t_{t} t^{2}-t_{a}{ }^{2}\right)-0.0053 \times 10^{-6}\left(t_{t}^{3}-t_{a}{ }^{3}\right)\right\}
\end{aligned}
$$

そして，この式によつて $t_{s}$ を Round number にとつて $\left(H_{t}, t_{t}\right)$ を算定した結果が Table 1 であり， $H-t$ 線図 にしたのが.Fig. 1 の実線である。他はそれぞれ图中に 註記した温度範囲の積分平均比熱によるるので，これら の誤差の一例を次の計算例で示す该註 2)。

[計算例] 大気が $H=0.015$ であるとして，これを $700^{\circ} \mathrm{C}$ まで予熱した後に断熱冷却で飽和させる時に，仮 りに $1400^{\circ} \mathrm{C}$ までの皘分平均のるので扱うと $\left(H_{8}-H\right)$ の值に約 $4 \%$ 正の誤差を生じ，この飽和空気を再び $700^{\circ} \mathrm{C}$ に加熱して同様に断熱冷却で飽和させる時には同 じく約 $9 \% の$ 正の誤盖が生ずる。また反対に，元の空気

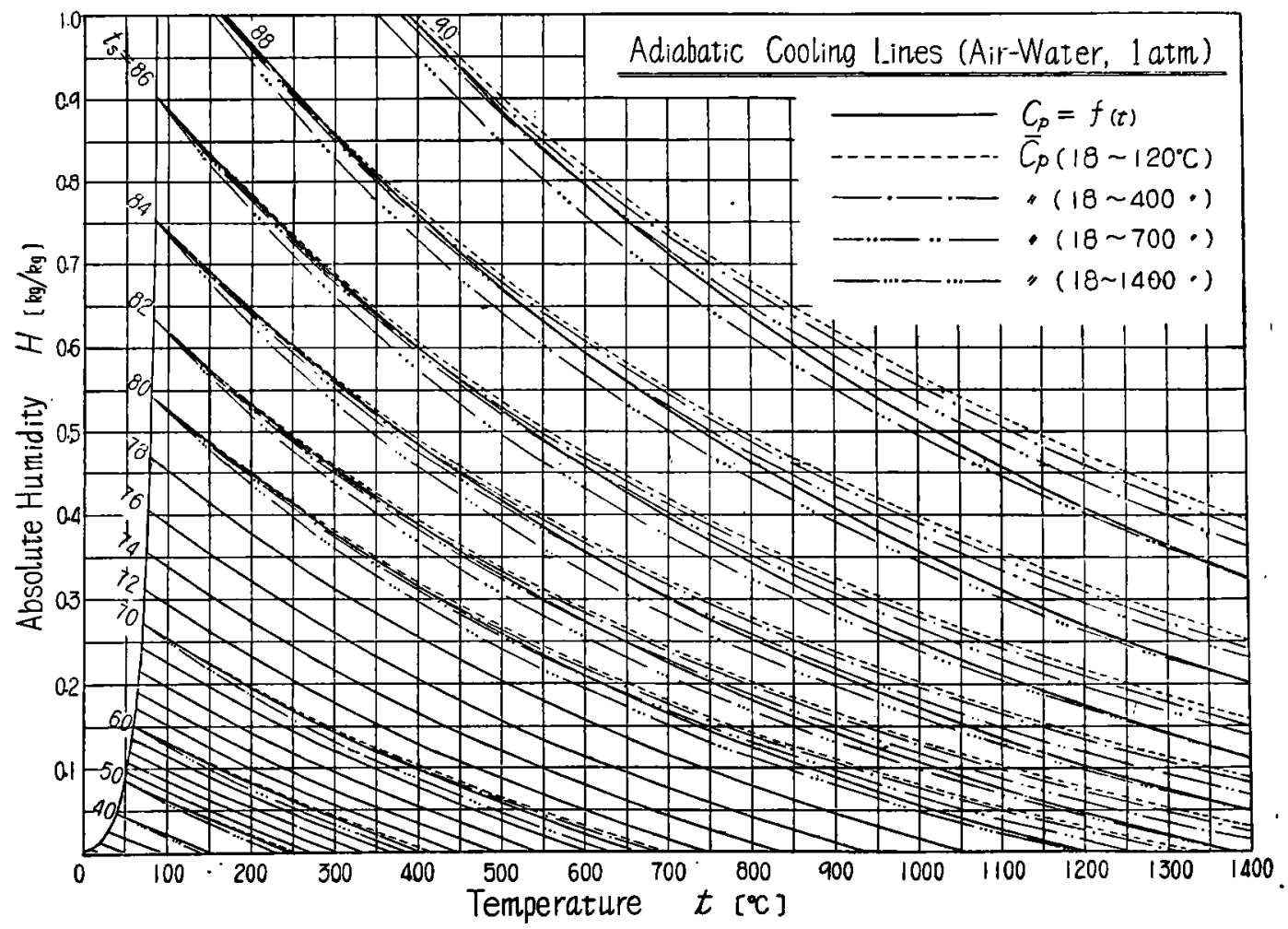

Fig. 1 Adiabatic cooling lines for air-water vapor system at normal pressure, by various equations. 
を $1,400^{\circ} \mathrm{C}$ まで予熱してから断熱冷却て飽和させる時 にもしも $700^{\circ} \mathrm{C}$ までの樍分平均のるので扱ろと今度は $\left(H_{s}-H\right)$ の値に約 $5 \%$ の負の誤差を生ずる。

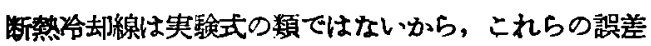
を許容することは適当でない。また，いろいろな温度範 囲の平均比熱で圾つたものを用意する位ならば，比熱を 温度の函数にしたるのを用意する方がよい。一つで温 度範围の如何にかかわらず正確だからである。このため の上式の計算は帡来のすのより多少面倒で, Fig.1 1 は比

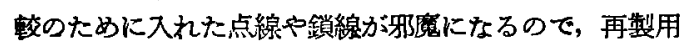
$に$ Table 1 を附した。Flash drying の場合のごとき温 度の使用範囲を考えこと, やはり比熱を温度の函数とし たすのを作つて低温です高温でも誤差なく使えるように する意義が生ずると思われる。

\section{$\S 9$ 結 語}

空気と水蒸気の比熱を温度の函数としても断熱飽和線 そ断熱冷却線は同じあのであることが裃明され，また従 来の比較的低温䉐囲で比熱を一定としたものを高温に補 外することはもちろんのこと高温との平均比熱を用いて あ誤差は相当大であることが判明した。

広い、温底範囲に亘つて使用する場合には比熱を温度の 函数として扱つた線図を使用することを提唱し，そのた めの計算值表を添附した。

なお，本報では水温を一定とする従来の定義が $90^{\circ} \mathrm{C}$ 位までる適用されると仮定し，且つ発生蒸気と空気の混 合熱の如きすのす考之ていない。

[附記]本報の計算と作目纹遠藤他数名加分担した。

後語 1) 比熱は一定としての同じことであるから，筒のため

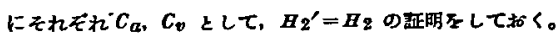

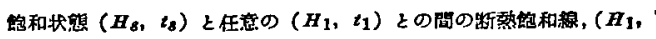

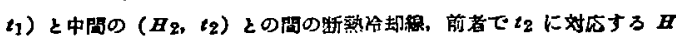
そ $H_{2^{\prime}}$ とした時のけのの 3 つの式はを机でれ

Table 1 Calculated $H$ vs $t$ values of adiabatic cooling lines [Air-water, 1 atm, $\left.C_{\text {air }} \& C_{\text {vap }}=f(t)\right]$

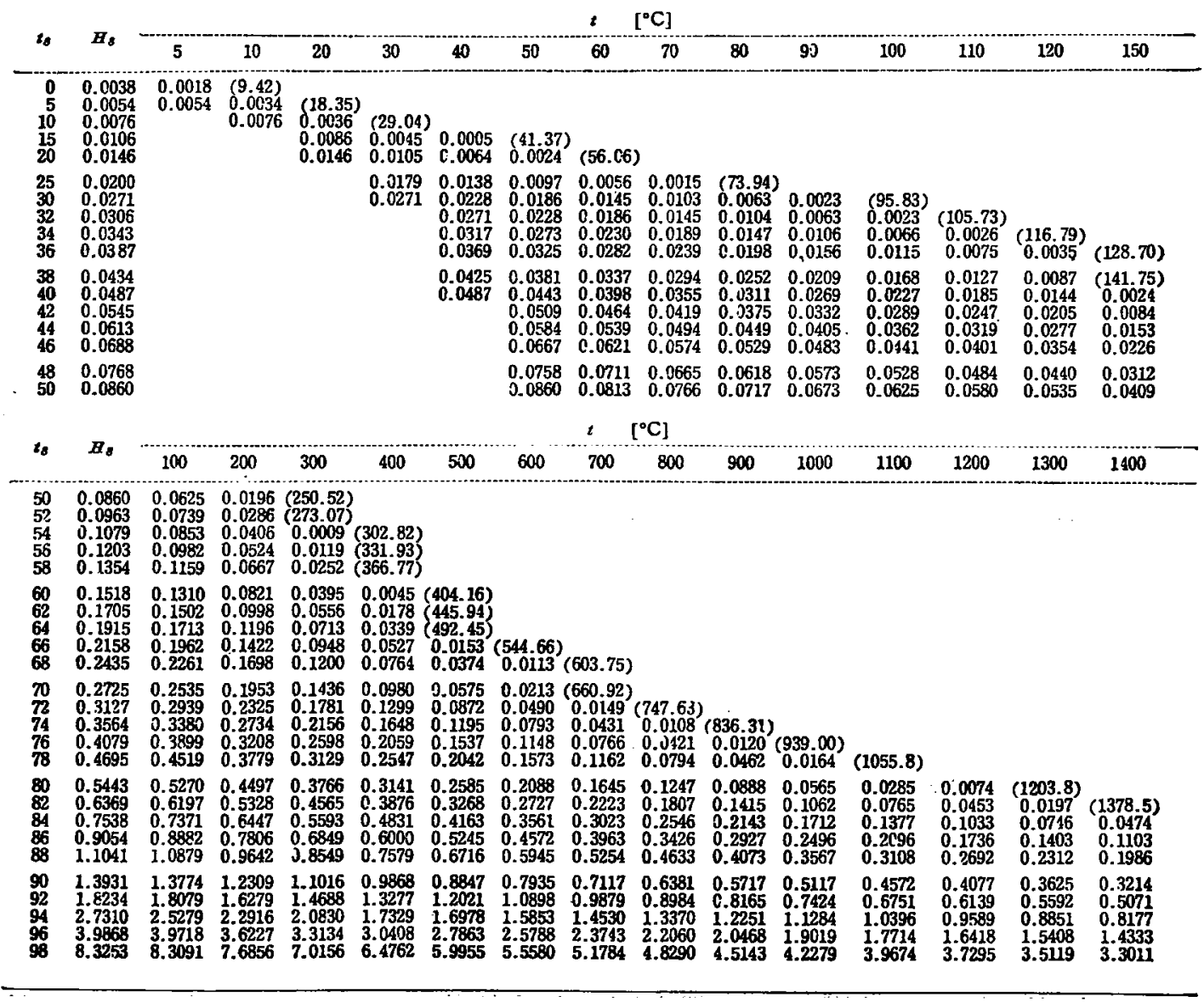




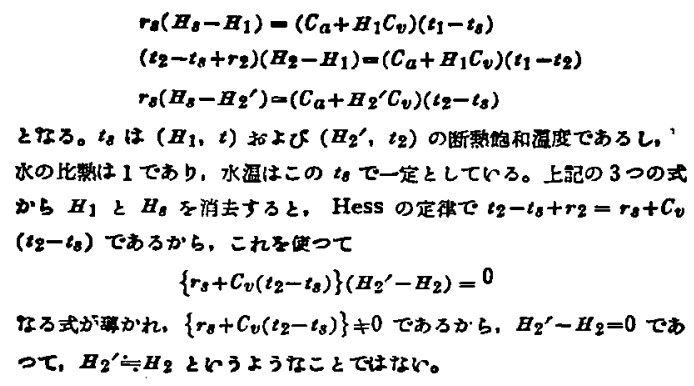

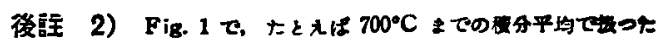

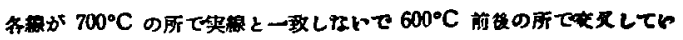

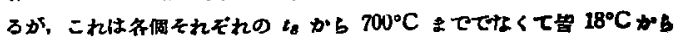

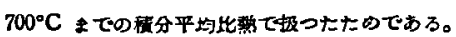

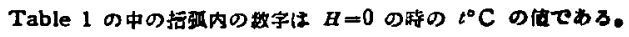
引用交献

1) 化学栾诚塧会：化学工学辞典

2) Hougen \& Watson : Chem. Process Principles, D. 242 (1950)

3) itut , p. 216

4) tlit, D. 214

\section{On the Adiabatic Cooling Lines when the Specific Heats of Air and Water Vapor are taken as Functions of Temperature.}

Takao Satoh and Etsuo Endoh

In treating the adiabatic cooling lines, the specific heats of air and water vapor have both been taken as constants. But this does not hold good when applied to the broad range of temperature.

In this report, the formula and chart of the adiabatic cooling lines, which have specific heats as the functions of temperature, are presented to show air-water vapor system at normal pressure.

The formula derived is :

$$
r_{s}\left(H_{s}-H\right)=\int_{t_{s}}^{t} C_{\mathrm{air}}(t) d t+H \int_{t_{s}}^{t} C_{\mathrm{vaD}}(t) d t
$$

Fig. 1 represents the chart, in which the comparisons are shown. In this case, too, adiabatic saturation lines conform to adiabatic cooling or adiabatic humidification lines. This relation is also verified in this report.

(45ページよりつつ゚く)

1919 年, テクノクラシーの父 Veblein の論交が 公刊され，The doctorine of Abundance $の$ 上に アメリカの技術主義思想が広ま $\boldsymbol{y}$ ，化学工学が成立 した。すれわれがここで見るすのは化学工学成立の 背景ですり，前記の Science の一部としてのエ学 の独立ではなく，より近代的な，アメリカ的な特質 のろちでエ工学の成立である。その一面は或は, 教 有としての独立性が特珠的なるのではなくて，一般 的, 社会的なるのであつたということ, 即ち, テク ノクラシー, プラグマチスム, マスプロの思想をだ ククとした工学の成立であり，アォリカに招いて成
立し得た一原因が見出されるとる考えられる。その 成立が，上り対象に强制される性格であつたために その方法に対す百統一性の欠点をるつと同時に，そ の対象の社会性のらちに統一性がより明らかに表わ されているのである。

その奶象をあつか5限界領域の方法として道入さ れ，一般に理解されている化学工学怔，化学阵根学 でない,ノミナルなるのでない発達をとげるために はその社会的地盤一の反省が必要であろう。そして てれには今後の努力が要求されている。

It is the true office of history to represent the events themselves, together with the consels, and so leave the observations and conclusions thereupan the liberty and faculty of every man's judgment — Sir Francis Bacon.

(遠藤一夫) 